\section{Association between cognitive impairment and presence of the apolipoprotein $E$ epsilon4 allele in elderly patients with major depressive disorder}

Associação entre declínio cognitivo e presença do alelo epsilon 4 da apolipoproteina E em pacientes idosos com transtorno depressivo maior

Diana Moitinho Bezerra, ${ }^{1}$ Quirino Cordeiro, ${ }^{2}$ Eduardo Yoshio Nakano, ${ }^{3}$ Homero Vallada, ${ }^{2}$ Cássio Machado de Campos Bottino

${ }^{1}$ Master student, Institute of Psychiatry, School of Medicine, Universidade de São Paulo (USP), São Paulo, SP, Brazil. Old Age Project (Projeto Terceira Idade, PROTER) Institute of Psychiatry, School of Medicine, USP. ${ }^{2} \mathrm{PhD}$. Psychiatrist. Institute of Psychiatry, School of Medicine, USP. ${ }^{3}$ MSc. Professor, Department of Statistics, Universidade de Brasília (UnB), Brasília, Brazil. ${ }^{4} \mathrm{PhD}$. Psychiatrist. Institute of Psychiatry, School of Medicine, USP. Old Age Project (Projeto Terceira Idade, PROTER) Institute of Psychiatry, School of Medicine, USP.

Dear Editors,

Major depressive disorder in late life is a very heterogeneous illness, and the neurobiological bases of this condition remain unclear. ${ }^{1}$ Recent investigation has hypothesized that the apolipoprotein E epsilon4 (ApoE4) allele could be associated with late-life depression. ${ }^{2}$

ApoE4 is a well-established risk factor for late-onset Alzheimer's disease. Varying degrees of cognitive dysfunction have been described in non-demented individuals with one or two epsilon4 alleles, leading to suggestions that the gene could play a role in cognitive impairment. ${ }^{3}$ This knowledge has generated interest in the influence of ApoE variants on cognition in different psychiatric conditions. Thus, we have performed a study in order to investigate the role of the ApoE4 allele in the cognition of patients with major depressive disorder according to the criteria established by the Diagnostic and Statistical Manual of Mental Disorders, 4th edition (DSM-IV).

Thirteen elderly patients older than 60 years [nine women $(69.2 \%)$ and four men $(30.8 \%)]$, all of them with a diagnosis of major depressive disorder according to DSM-IV criteria, were included in the study. Blood samples of all subjects were collected for genetic investigation. Patients were divided into two groups, according to the presence or absence of the ApoE4 allele (ApoE4 and non-ApoE4 groups). Genotyping was performed by two investigators according to Hixson \& Vernier, ${ }^{4}$ using the HhaI restriction enzyme. In order to avoid errors, genotyping was repeated when the results of both trained investigators were not the same. All patients provided written informed consent, and the study protocol was approved by the Research Ethics
Committee at Hospital das Clínicas da Faculdade de Medicina da Universidade de São Paulo, São Paulo, Brazil.

Cognitive impairment was assessed by submitting the patients to a neuropsychological evaluation which included the cognitive test of the Cambridge Examination for Mental Disorders of the Elderly (CAMCOG) and the Mini-Mental State Examination (MMSE). The presence of depressive symptoms was assessed using the Montgomery-Åsberg Depression Rating Scale (MADRS). Significance was set at $\mathrm{p}=0.05$.

Statistical analyses showed an association between presence of ApoE4 and cognitive impairment measured by CAMCOG (Table 1). There was a trend of association between cognitive impairment measured by MMSE and the investigated allele (Table 1). Age and educational level did not differ after the two groups were compared by an independent $t$ test (age, $p=0.975$; years at school, $p=0.137$ ). There was no difference between the groups in terms of depressive symptoms investigated using MADRS $(\mathrm{p}=0.124)$.

Table 1 - Cognitive performance and ApoE4 distribution

\begin{tabular}{lccc}
\hline & \multicolumn{2}{c}{ Depressed elderly } & \\
\cline { 2 - 3 } & ApoE4 & Non-ApoE4 & p \\
\hline CAMCOG & $68.88 \pm 18.43$ & $90.20 \pm 11.52$ & $0.026^{*}$ \\
MMSE & $21.25 \pm 5.01$ & $26.60 \pm 3.85$ & $0.055^{*}$ \\
\hline Results presented as means \pm standard deviation. * Student t-test &
\end{tabular}

According to our findings, the presence of the ApoE4 allele was associated with greater cognitive impairment in older patients with major depressive disorder. We also found that cognitive impairment was not influenced by age, educational level, or severity of depressive symptoms. In a recent report, ApoE4 was found to be an independent contributor to cognitive decline in a community-based sample. ${ }^{5}$ Thus, ApoE4 may act disrupting neurological functioning, which in turn may reduce the individuals' cognitive reserve capacity. ${ }^{5}$ Such results support the hypothesis that the presence of ApoE4 may be associated with cognitive impairment in elderly depressive patients.

\section{References}

1. Avila R, Bottino CM. Cognitive changes update among elderly with depressive syndrome. Rev Bras Psiquiatr. 2006;28(4):316-20.

2. Yen YC, Rebok GW, Gallo JJ, Yang MJ, Lung FW, Shih CH. ApoE4 allele is associated with late-life depression: a population-based study. Am J Geriatr Psychiatry. 2007;15(10):858-68.

3. Christensen H, Batterham PJ, Mackinnon AJ, Jorm AF, Mack HA, Mather KA, et al. The association of APOE genotype and cognitive decline in interaction with risk factors in a 65-69 year old community sample. BMC Geriatr. 2008;14(8):1-10.

4. Hixson JE, Vernier DT. Restriction isotyping of human apolipoprotein E by gene amplification and cleavage with HhaI. J Lipid Res. 1990;31(3):545-8.

5. Corsentino EA, Sawyer K, Sachs-Ericsson N, Blazer DG. Depressive symptoms moderate the influence of the apolipoproteine epsilon4 allele on cognitive decline in a sample of community dwelling older adults. Am J Geriatr Psychiatry. 2009;17(2):155-65.

Correspondence:

Diana Moitinho Bezerra, di_piparoti@yahoo.com.br

No conflicts of interest declared concerning the publication of this letter

Copyright (C) Revista de Psiquiatria do Rio Grande do Sul - APRS

Submitted Feb 26, 2010. Accepted Mar 09, 2010. 